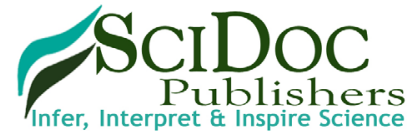

International Journal of Clinical Therapeutics and Diagnosis (IJCTD)

ISSN 2332-2926

\title{
Medico-Legal Evaluation of Sudden Cardiac Deaths in Albania, 2014-2015
}

Review Article

Lloja $\mathrm{A}^{1}$, Sinani $\mathrm{F}^{1}$, Petku I², Sinani $\mathrm{L}^{2}$, Vyshka $\mathrm{G}^{2 *}$, Xhemali B ${ }^{1}$

${ }^{1}$ Department of Forensic Pathology, Institute of Legal Medicine, Tirana, Albania.

${ }^{2}$ Faculty of Medicine, University of Medicine in Tirana, Albania.

Abstract

Sudden cardiac death is an occurrence of extreme severity, with medical, legal, social and public health implications. We have studied the forensic registers with regard to sudden deaths due to heart disease during the years 2014 and 2015 consecutively. Several large scale studies are available, aiming at profiling the risk factors and groups of patients prone to suffer from this event, as well as proposing preventive measures. In our study years, there was a clear male preponderance of sudden deaths due to heart disease; an age profile could be identified as well. An increase in the heart weight beyond normal values as well as the presence of atherosclerosis, its severity, and the mere fact that these preconditions might go undiagnosed and therefore untreated for long periods of time; all these situations need attention and accurate addressing. Being this the second study of our facility on this issue, we can as well compare findings and their evolution from time to time, together with confronting those with other sources reporting on the same theme.

Keywords: Sudden Cardiac Death; Mortality; Legal Medicine; Public Health.

\section{Introduction}

Sudden cardiac death [SCD] is a major public health issue, since already years before the mortality related to cardiac conditions approximates one third of the totality of fatal cases [1]. Authors have already mentioned an ever enlarging list of causes, with ventricular arrhythmias being probably on the top, together with the coronary thrombosis as a final event of an otherwise longdating coronary disease $[2,3]$.

Due to the dramatic nature of the occurrence, large epidemiological and pathological studies have been performed, trying to point out risk factors and eventually to draft preventive interventions. Among peculiarities related to a SCD event, circadian rhythms have been included and imputed, with sources suggesting a peak during the early morning hours, especially in the immediacy of after awakening $[4,5]$. Serious attempts have been made to identify trigger factors, with sympathetic hyperactivity and stimulation being mentioned as a first-hand hazard [6]. Exhaustive reviews are available as well, but authors underline that although identifying the prodrome of SCD has attracted considerable interest, unfortunately the majority of the patients pass away without even contacting a physician [7].

There is, beyond reasonable doubts, a time profile in the distribution of SCD events; not only with regard to the day hours i.e. the circadian timing, but with regard to weekly day and seasonal distribution $[8,9]$. A study of the physiological changes related to any precise time profiling, such as for example morning changes; seasonal homeostatic and physiological adaptations, might lead to a better understanding of the SCD pathogenesis. And after all, in spite of all advances made in the diagnosis and treatment of cardiac conditions, heart disease remains the number one cause of death, with half of these deaths occurring suddenly [10].

\section{Materials and Methods}

Forensic medical facilities in Albania have a centralized register, and our data report occurrences covering the entirety of the national territory. Previously we have reported some data of our own with regard to SCD in Albania, in earlier years, already trying to focus on detection of risk factors and framing of preventive measures, as applicable as those might be [11].

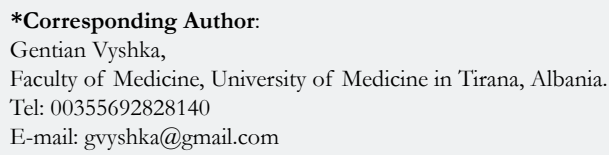

Citation: Lloja A, Sinani F, Petku I, Sinani L, Vyshka G, Xhemali B. Medico-Legal Evaluation of Sudden Cardiac Deaths in Albania, 2014-2015. Int J Clin Ther Diagn. 5(2), 136-139. doi: http://dx.doi.org/10.19070/2332-2926-1700026

Copyright: Vyshka $\mathbf{G}^{\circ}$ 2017. This is an open-access article distributed under the terms of the Creative Commons Attribution License, which permits unrestricted use, distribution and reproduction in any medium, provided the original author and source are credited. 
The actual data presented in this paper cover the two-year period of time of 2014 and 2015. Forensic registers at the Institute of Legal Medicine, Tirana, were consulted with regard to SCD for the years 2014 and 2015. During this two-year period of study we had a total registered of 48 sudden cardiac deaths during 2014; and 56 SCD cases during 2015 [a total of 104 cases of SCD]. Male predominance of cases was obvious, with $79 \%$ of the total number [ 82 cases]. Females with SCD during this two-year period were only 22 in the total, thus clearly in a minority [Figure 1].

Figure 2 illustrates the total events separated according to age groups. With regard to our study group we have had a predominance of lethal cases in the age group 55-59 years old [28
SCD cases]. This age group was followed from the 70-79 years old age group [with 21 fatal cases or 20, $2 \%$ of the total]; followed from the age group 60-69 years old [with 19 fatalities or 18, 3\% of the total].

Following the evaluation of the heart weight, we have found that almost $72 \%$ of cases had an increased volume, as considered from the examining coroner. In another $11 \%$ of the cases the weight was normal. In another $3 \%$ of the cases we had a heart weight of 400-490 grams [3 fatalities]. In only one case the heart weighted more than 800 grams, a value which is abundantly above normal ranges.

Figure 1. Gender profile of the cases included in the study group, separated for the two years of the study (2014, 2015).

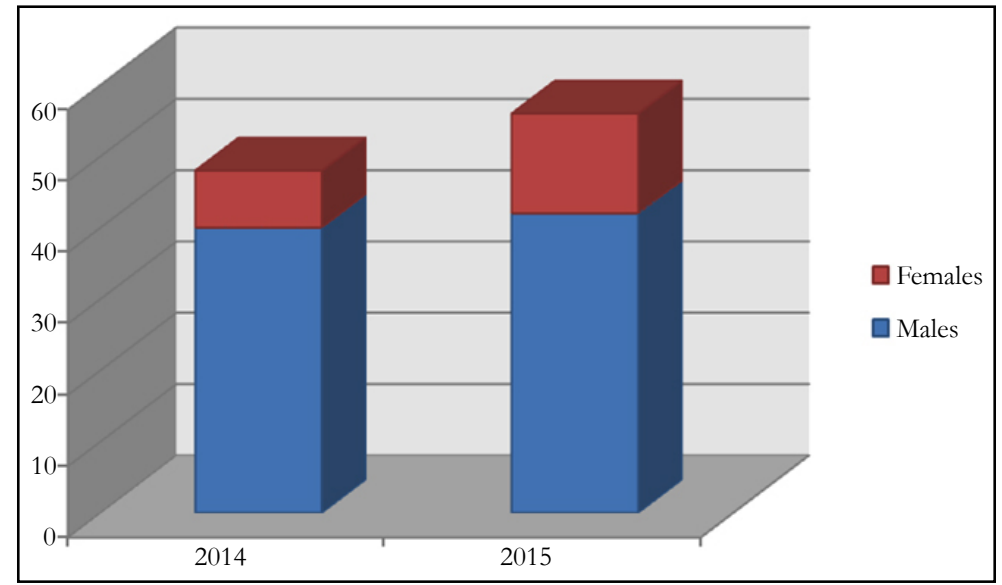

Figure 2. Age subgroups of the SCD cases (2014-2015).

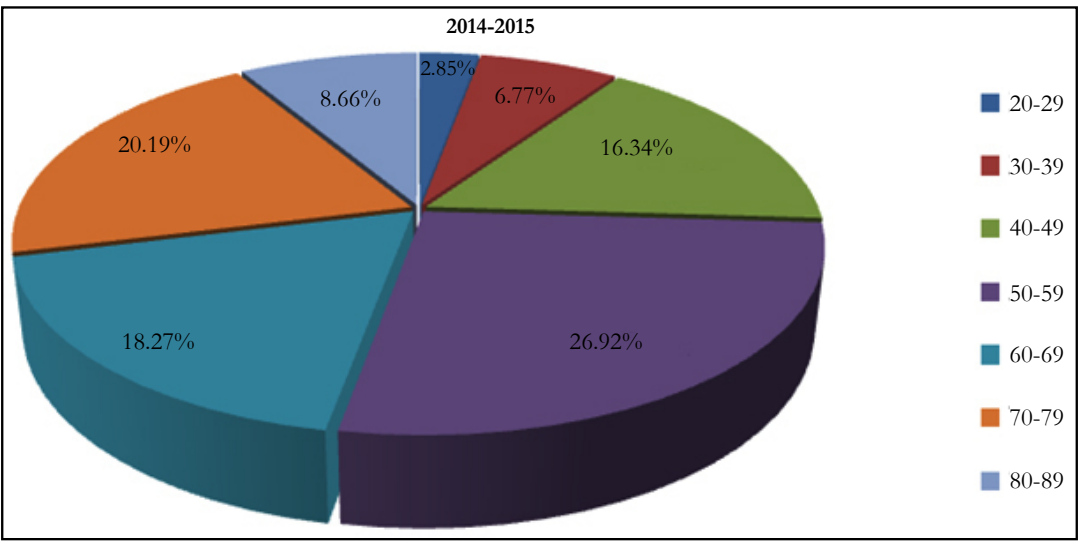

Figure 3. Heart weight in the study group for both years; in grams.

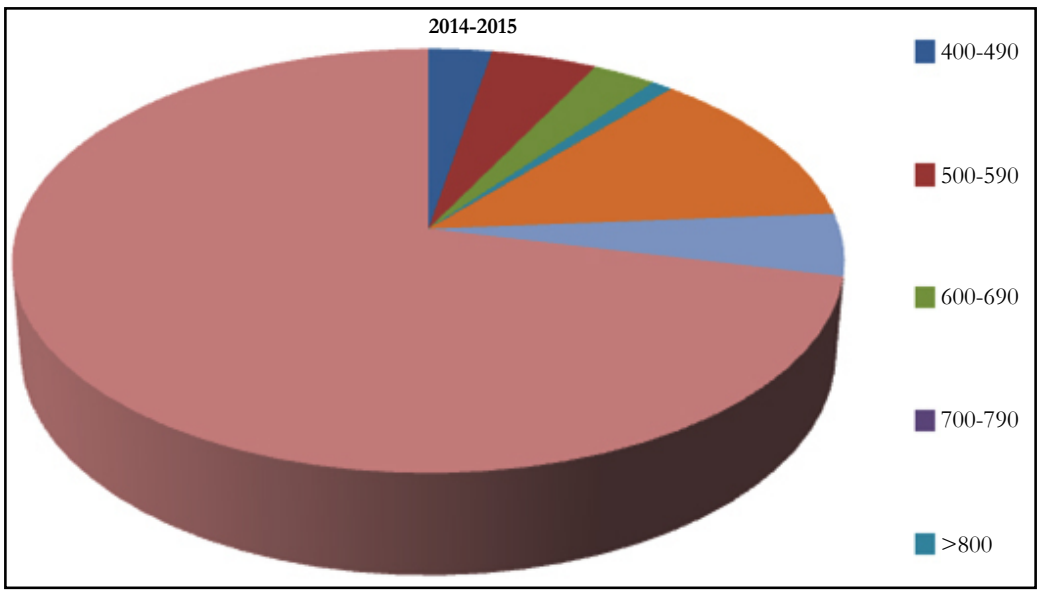


The evaluation of coronary arteries lumen, diameter and presence of subclinical stenosis or other signs of atherosclerosis is as well highly important in the case of SCD. In our study group we found atherosclerosis as evident in 65 cases; only 16 cases were excluded from having detectable atherosclerosis. In another 21 cases we could not gather reliable data.

It is therefore clear that presence of atherosclerosis $[62,5 \%$ in our study group] is highly important for investigating the level of risk for coronary heart disease. We have classified the level of atherosclerotic stenosis in four grades, with a stenosis of fourth grade higher than $75 \%$ obstruction of the viable lumen; third grade of $50-75 \%$; second grade such as of $25-50 \%$ and first less than $25 \%$ of stenotic occurrence. Grading stenosis is a highly applicable form of evaluating coronary risk, and our data refer to a three-vessel assessment; therefore we made a total evaluation, which might create biases with regard to single arteries' state of viability. In some cases it was impossible to collect data with regard to coronary arteries' status [Figure 4].

The final diagnosis such as registered in the medical files of the fatalities composing our study group was mostly acute myocardial infarction [ 63 cases]; 12 cases were defined as acute heart failure; another 23 cases as cardiorespiratory failure, and 6 last cases as cardiogenic shock. The figure below [5] shows the respective distribution of the diagnosis leading to the final lethal event.

\section{Discussion}

SCD is recently being considered as not merely a public health, but also as a safety issue [12]. Therefore and in almost all cases, a careful and detailed medico-legal evaluation is needed, even when before an old suffering cardiac patient passing away at the end stage of the disease.

With the advances of genetics and molecular science, channelopathies have come into attention and the opinion of appropriate specialists might be requested even posthumously [13]. Lethal arrhythmias may remain silent or subclinical for long periods of time, with death only uncovering the presence of major risk factors for SCD. A diversity of genetic conditions predispose for the occurrence, such as familial long QT syndrome, Brugada syndrome, catecholaminergic polymorphic ventricular tachycardia, and inherited cardiomyopathies [14].

Attempts to sketch a methodology for identifying situations at risk include not only genetic counselling, but also the cardiac enzymes profile, heart imaging [MRI] and even the use of very old examinations such as the surface ECG [15-17]. However, whenever facing the unlucky occurrence of a SCD, the last call will be obviously the one of a pathologist. The coroner or the

Figure 4. Stenosis in the coronary arteries of study group for both years (First degree with a stenosis considered as less than $25 \%$; highest degree being the fourth with $>75 \%$ of lumen stenosis).

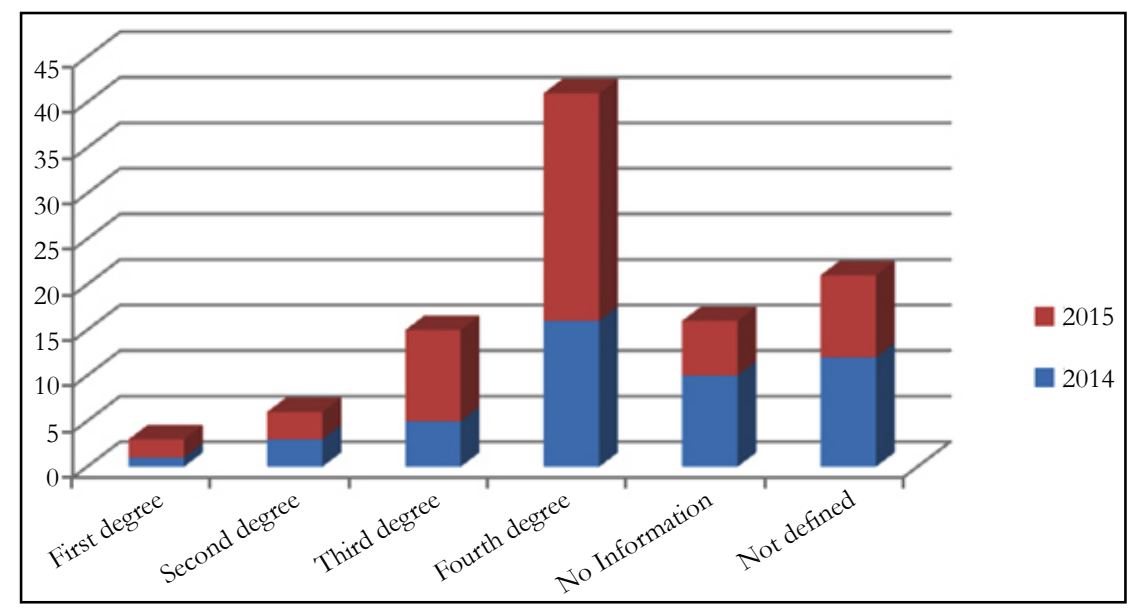

Figure 5. Distribution of admission diagnoses during the fatal event; entire study group (2014-2015).

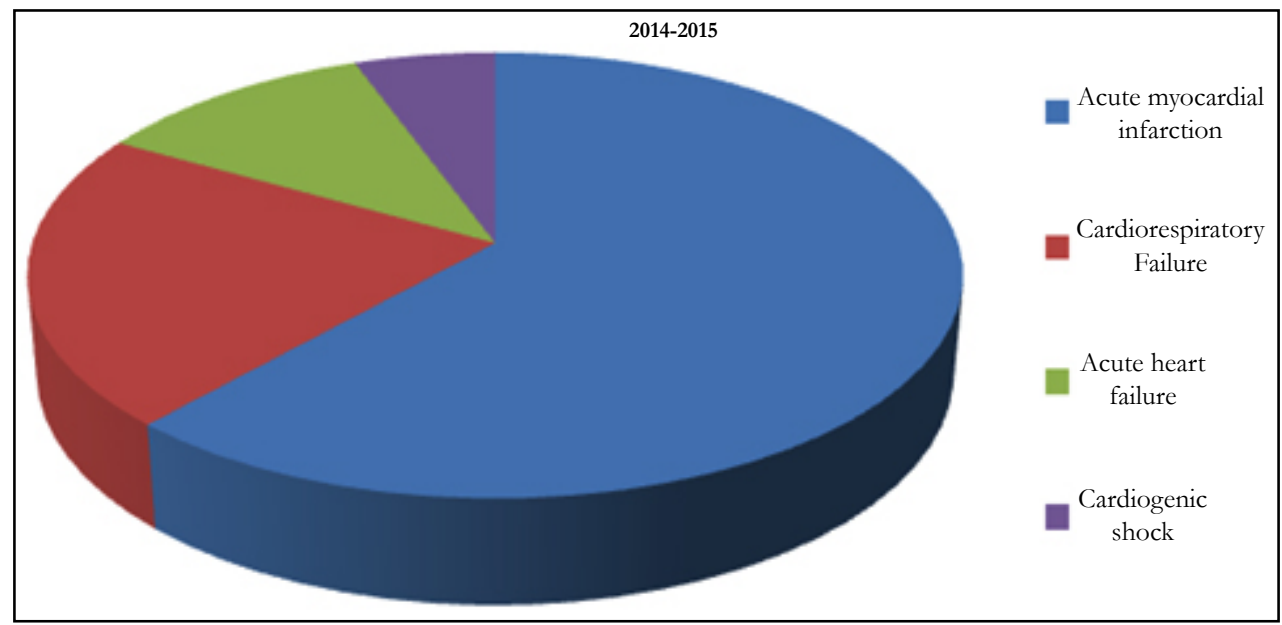


legal expert performing the autopsy needs therefore a thorough knowledge of normal heart anatomy, variations, as well as abnormal microscopic or macroscopic findings of the organ; with some sources even suggesting that the reporting should be mandatory [18].

\section{Conclusions}

Sudden cardiac death is an issue of high medical and legal importance. Although the data collected in our facility needs validation through other, probably of larger scale studies, it seems clear that SCD has a male predominance, and the group from 55 to 59 years old represents the mostly risked age. According to our data SCD has as well a direct connection with the level of atherosclerosis (evaluated as percentage of lumen stenosis in the coronary arteries) and with the excessive weight of the heart, a common finding in long-dating or untreated cardiomyopathies of different origin. In the era of coronarography as a routine diagnostic tool, and with panoply of cardiac imaging techniques at hand, early diagnosis and preventive measures seem feasible and at reach.

\section{References}

[1]. Mehra R. Global public health problem of sudden cardiac death. J Electrocardiol. 2007 Dec;40(6 Suppl):S118-22. PubMed PMID: 17993308.

[2]. John RM, Tedrow UB, Koplan BA, Albert CM, Epstein LM, Sweeney MO, et al. Ventricular arrhythmias and sudden cardiac death. Lancet. 2012 Oct 27;380(9852):1520-9. PubMed PMID: 23101719.

[3]. Virmani R, Burke AP, Farb A. Sudden cardiac death. Cardiovasc Pathol. 2001 Oct;10(5):211-8. PubMed PMID: 11673058.

[4]. Muller JE, Ludmer PL, Willich SN, Tofler GH, Aylmer G, Klangos I, et al. Circadian variation in the frequency of sudden cardiac death. Circulation. 1987 Jan;75(1):131-8. PubMed PMID: 3791599.

[5]. Willich SN, Goldberg RJ, Maclure M, Perriello L, Muller JE. Increased onset of sudden cardiac death in the first three hours after awakening. Am J Cardiol. 1992 Jul;70(1):65-8. PubMed PMID: 1615872.
[6]. Willich SN, Maclure M, Mittleman M, Arntz HR, Muller JE. Sudden cardiac death. Support for a role of triggering in causation. Circulation. 1993 May;87(5):1442-50. PubMed PMID: 8490998

[7]. Mahmoud KD, de Smet BJ, Zijlstra F, Rihal CS, Holmes DR Jr. Sudden cardiac death: epidemiology, circadian variation, and triggers. Curr Probl Cardiol. 2011 Feb;36(2):56-80. PubMed PMID: 21356429.

[8]. Arntz HR, Müller-Nordhorn J, Willich SN. Cold Monday mornings prove dangerous: epidemiology of sudden cardiac death. Curr Opin Crit Care. 2001 Jun;7(3):139-44. PubMed PMID: 11436519.

[9]. Arntz HR, Willich SN, Schreiber C, Brüggemann T, Stern R, Schultheiss HP. Diurnal, weekly and seasonal variation of sudden death. Populationbased analysis of 24,061 consecutive cases. Eur Heart J. 2000 Feb;21(4):31520. PubMed PMID: 10653679.

[10]. Vandenberg JI, Perry MD, Hill AP. Recent advances in understanding and prevention of sudden cardiac death. F1000Res. 2017;6:1614. Doi: 10.12688/ f1000research.11855.1. PubMed Central PMCID: PMC5583740.

[11]. Sinani F, Xhemali B, Vyshka G, Sinani L, Çipi B. A Forensic Approach to Sudden Cardiac Death. Int J Public Health Res. 2015 Aug;3(4):130-134.

[12]. Ackerman M, Atkins DL, Triedman JK. Sudden Cardiac Death in the Young. Circulation. 2016 Mar 8;133(10):1006-26. PubMed PMID: 26951821.

[13]. Fernández-Falgueras A, Sarquella-Brugada G, Brugada J, Brugada R, Campuzano O. Cardiac Channelopathies and Sudden Death: Recent Clinical and Genetic Advances. Biology (Basel). 2017 Jan 29;6(1). Pii: E7. Doi: 10.3390/biology6010007. PubMed PMID: 28146053.

[14]. Semsarian C, Ingles J. Molecular autopsy in victims of inherited arrhythmias. J Arrhythm. 2016 Oct;32(5):359-365. Epub 2015 Nov 19. PubMed PMID: 27761159.

[15]. Hładij R, Rajtar-Salwa R, Dimitrow PP. Troponin as ischemic biomarker is related with all three echocardiographic risk factors for sudden death in hypertrophic cardiomyopathy (ESC Guidelines 2014). Cardiovasc Ultrasound. 2017;15(1):24. PubMed Central PMCID: PMC5598038.

[16]. Holmes AA, Romero J, Levsky JM, Haramati LB, Phuong N, Rezai-Gharai $\mathrm{L}$, et al. Circumferential strain acquired by CMR early after acute myocardial infarction adds incremental predictive value to late gadolinium enhancement imaging to predict late myocardial remodelling and subsequent risk of sudden cardiac death. J Interv Card Electrophysiol. 2017 Nov 15. Doi: 10.1007/s10840-017-0296-9. PubMed PMID: 29143170.

[17]. Abdelghani SA, Rosenthal TM, Morin DP. Surface Electrocardiogram Predictors of Sudden Cardiac Arrest. Ochsner J. 2016;16(3):280-9. PubMed Central PMCID: PMC5024811.

[18]. Campbell RM, Berger S, Ackerman MJ, Batra AS. Call for a sudden cardiac death registry: should reporting of sudden cardiac death be mandatory? Pediatr Cardiol. 2012 Mar;33(3):471-3. PubMed PMID: 21861145. 